\title{
Residential Telephone Number
}

National Cancer Institute

\section{Source}

National Cancer Institute. Residential Telephone Number. NCI Thesaurus. Code C81284.

The sequence of numbers or characters, that when dialed, connects to a particular residential telephone. 